\title{
Fisiologia da termorregulação normal
}

\section{Thermoregulation}

\section{José Reinaldo Cerqueira Braz}

Professor Titular do Departamento de Anestesiologia da Faculdade de Medicina de Botucatu, Universidade Estadual de São Paulo- UNESP.

\section{Fisiologia da Termorregulação Normal}

O homem necessita que a temperatura interna seja constante e o seu sistema termorregulador mantém a temperatura central próxima de $37^{\circ} \mathrm{C}$, para conservação das funções metabólicas ${ }^{1}$.

A manutenção da normotermia nos animais homeotermos, como o homem, é uma função muito importante do sistema nervoso autônomo. Já com pequenas alterações da temperatura central, podem ocorrer alterações metabólicas e enzimáticas ${ }^{2-4}$.

A termorregulação é realizada por um sistema de controle fisiológico, que consiste em termorreceptores centrais e periféricos, um sistema de condução aferente, o controle central de integração dos impulsos térmicos e um sistema de respostas eferentes levando a respostas compensatórias $^{2}$ (Figura 1).

No hipotálamo situa-se o sistema de controle central, que regula a temperatura do corpo ao integrar os impulsos térmicos provenientes de quase todos os tecidos do organismo, e não apenas em relação à temperatura central do organismo, o que tem sido considerado como temperatura corporal média. Quando o impulso integrado excede ou fica abaixo da faixa limiar de temperatura, ocorrem respostas termorreguladoras autonômicas, que mantêm a temperatura do corpo em valor adequado ${ }^{3}$.

Os impulsos termais aferentes provêm de receptores anatomicamente distintos ao frio e ao calor, os quais podem ser periféricos ou centrais ${ }^{4}$. Também existem receptores termossensíveis localizados na pele e nas membranas mucosas, que medeiam a sensação térmica e contribuem para a ocorrência dos reflexos termorregulatórios. Esses receptores também respondem à sensação mecânica. 


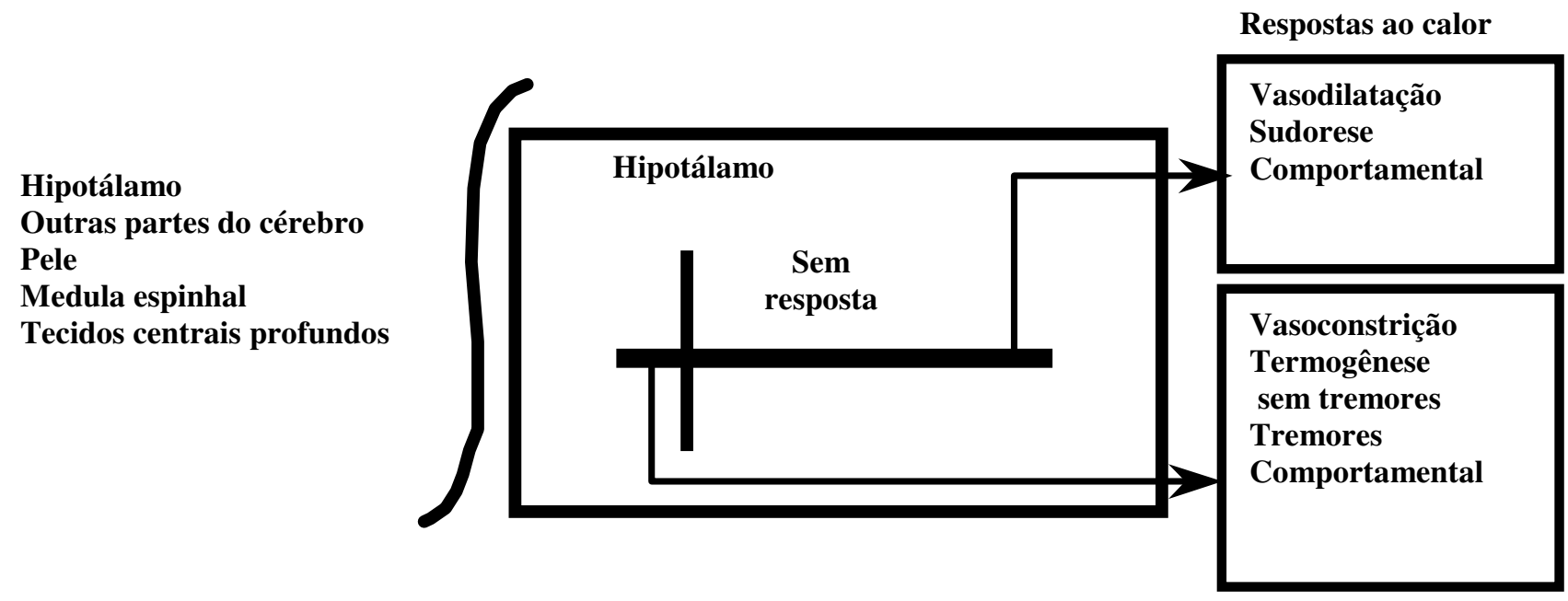

Respostas ao frio

Figura 1 - O modelo de termorregulação. Os impulsos térmicos recebidos dos tecidos periféricos são integrados no hipotálamo, o qual determina a temperatura corporal média. A faixa interlimiar é a temperatura corporal média durante a qual não são deflagradas respostas efetoras. Adaptado de Sessler (1994) ${ }^{6}$.

Os receptores para frio têm descargas de impulsos a temperaturas entre $25^{\circ}-30^{\circ} \mathrm{C}$ e são inervados por fibras $\mathrm{A} \delta$. Os receptores para calor têm descargas de impulsos a temperaturas entre $45^{\circ}-50^{\circ} \mathrm{C}$ e são inervados por fibras desmielinizadas $\mathrm{C}^{3}$.

No hipotálamo anterior é feita a integração das informações aferentes térmicas, enquanto no hipotálamo posterior iniciam-se as respostas efetoras. Na área pré-óptica do hipotálamo existem neurônios sensíveis e não sensíveis à temperatura, sendo que os primeiros podem ser classificados em neurônios sensíveis ao calor e neurônios sensíveis ao frio, estes últimos predominantes. Ressalte-se ainda a presença de neurônios sensíveis à estimulação térmica local no hipotálamo posterior, na formação reticular e na região medular ${ }^{5}$.

Existe uma faixa interlimiar de temperatura, definida geralmente entre $36,7^{\circ}$ a $37,1^{\circ} \mathrm{C}$, na qual não há resposta efetora. Temperaturas abaixo ou acima desses limiares desencadeiam respostas efetoras (Figura 2). Em pacientes anestesiados a faixa interlimiar pode chegar a $3^{\circ}$ $4^{\circ} \mathrm{C}$ de diferença, quando o normal é de $0,4^{\circ} \mathrm{C}$ de diferençá. Essa faixa é mais ampla no estado hipotérmico do que no hipertérmico, especialmente no paciente sob anestesia (Figura $3)$. 


\section{Paciente em vigília}

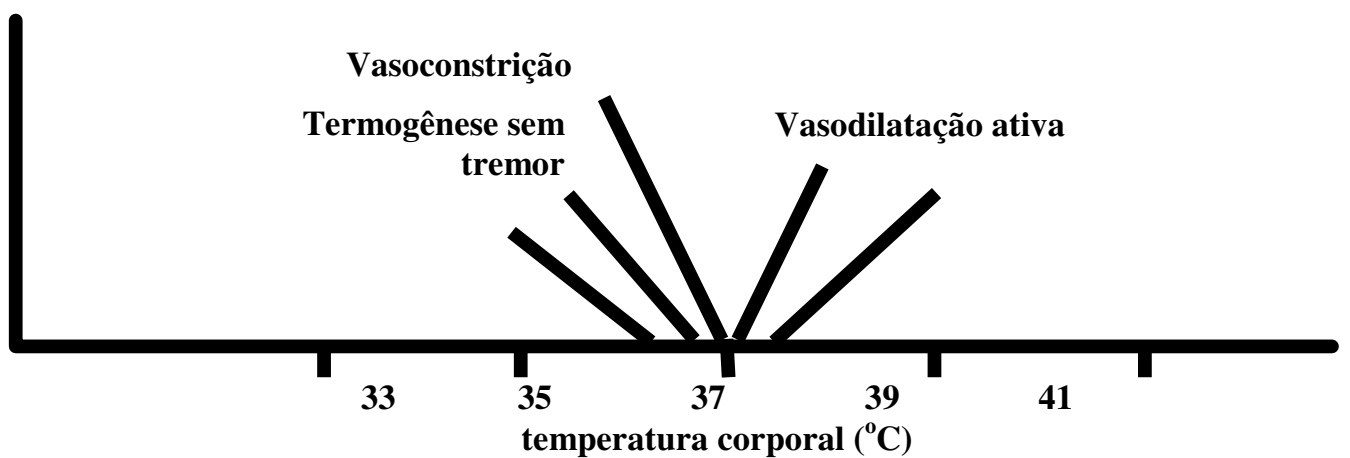

Figura 2 - Limiares termorreguladores em lactentes e crianças em estado de vigília. O eixo das ordenadas representa a intensidade máxima das respostas efetoras. Adaptado de Bissonette (1993) ${ }^{7}$.

O controle termorregulatório é semelhante no homem e na mulher ${ }^{8}$, mas diminui no idoso 9 e em pacientes gravemente enfermos.

A resposta comportamental é a resposta termorregulatória quantitativamente mais eficaz, porém vários outros mecanismos, também eficazes, são importantes, como a resposta vasomotora, que se caracteriza pela vasodilatação em resposta ao calor e pela vasoconstrição e piloereção em resposta ao frio; o tremor, que aumenta o consumo de oxigênio e a taxa metabólica em resposta ao frio; e a sudorese em resposta ao calor (Figuras 1 e 2).

Quando no termostato hipotalâmico há indicação de temperatura corporal fria, impulsos do hipotálamo se dirigem para o córtex cerebral, dando ao indivíduo a sensação de frio. O resultado é uma modificação comportamental, com aumento da atividade motora, colocação de agasalhos e movimentação para aumento do aquecimento. $\mathrm{O}$ controle das respostas comportamentais depende fundamentalmente da temperatura da pele.

Em relação ao calor, a primeira defesa autonômica é a vasodilatação cutânea. Já a sudorese, mediada por inervação colinérgica pós-ganglionar nas terminações glandulares, é considerada a mais importante. O suor é um ultrafiltrado do plasma e sua composição depende da intensidade da sudorese, do estado de hidratação e de outros fatores. Em situação máxima, o adulto produz mais de $0,5 \mathrm{~L} / \mathrm{h}$ de suor, principalmente o atleta bem treinado. A sudorese é um processo muito efetivo de perda de calor por causa do elevado calor latente de evaporação da água. Cada grama de suor que se evapora absorve 584 calorias. Conseqüentemente, a sudorese pode dissipar facilmente o calor especialmente se o ambiente 
estiver seco. A eficiência da sudorese é aumentada pela vasodilatação pré-capilar termorreguladora, resposta característica do homem, que é regulada por fatores como a bradicinina e o óxido nítrico. Ela aumenta, em muito, o fluxo sanguíneo cutâneo para facilitar a transferência do calor central para a pele.

\section{Paciente sob anestesia}

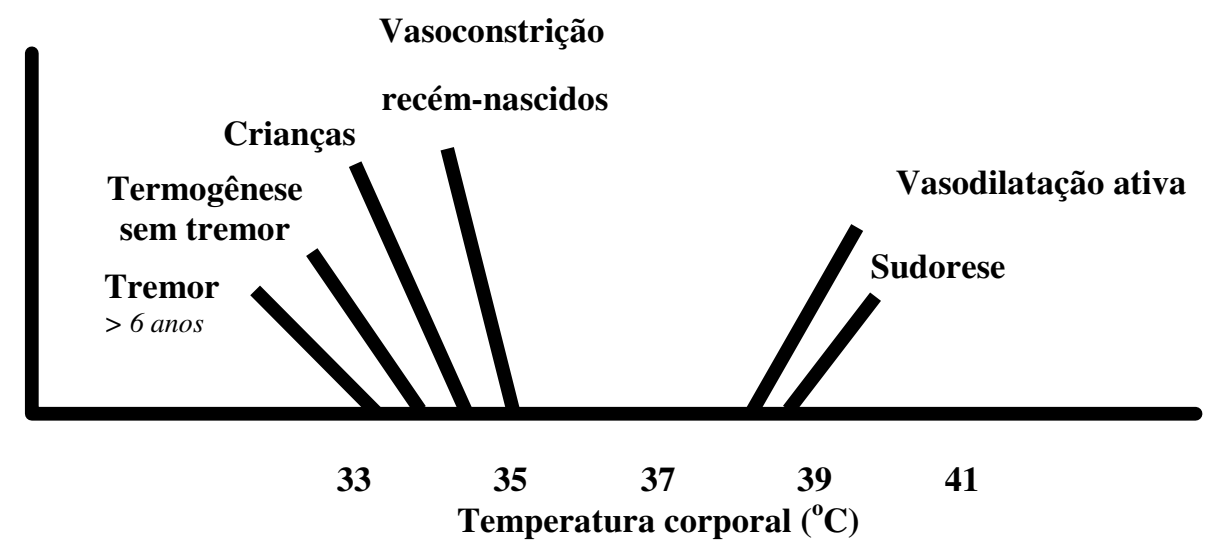

Figura 3 - Limiares termorreguladores em lactentes e crianças sob anestesia. $\mathrm{O}$ eixo das ordenadas representa a intensidade máxima das respostas efetoras. Adaptado de Bissonette (1993) ${ }^{7}$.

No caso de ocorrência de hipotermia, a resposta vasoconstritora é a primeira a ser deflagrada e é considerada a mais importante.

O fluxo sangüíneo da pele das extremidades pode ser dividido em dois compartimentos: o nutricional, representado pelos capilares, e o termorregulador, pelos curtocircuitos arteriovenosos situados principalmente nos dedos das mãos e dos pés, nas orelhas e no nariz ${ }^{10}$. Assim, na hipotermia, o fluxo sangüíneo pode ser diminuído em até 100 vezes por meio desses curto-circuitos. O fluxo dos curto-circuitos é mediado primariamente pela noradrenalina liberada nas terminações adrenérgicas pré-sinápticas que, ao ligar-se aos receptores $\alpha_{1}$-adrenérgicos, determina vasoconstrição ${ }^{10}$. Embora ocorra diminuição da perfusão cutânea pela vasoconstrição termorreguladora, a redução da perda de calor pelo organismo é pequena, ao redor de $25 \%$. As perdas pelas mãos e pelos pés diminuem ao redor de $50 \%$, mas somente $17 \%$ pelo tronco. 


\section{Locais de Monitorização da Temperatura Central}

Os locais mais utilizados para monitorização da temperatura corporal durante a anestesia são: nasofaringe, membrana timpânica, reto e esôfago. Outros locais também são utilizados, como bexiga, axila e artéria pulmonar, esta última quando o paciente apresenta monitorização hemodinâmica por meio de cateter de Swan Ganz colocado na artéria pulmonar.

A escolha do local para medição de temperatura corporal depende da sua finalidade, podendo estar relacionada à medição da temperatura de órgãos específicos ou da temperatura central. Assim, medições da temperatura na membrana timpânica ou nasofaringe estimam a temperatura cerebral. Já a temperatura esofagiana e a da artéria pulmonar aproximam-se da temperatura do miocárdio. Segundo os autores ${ }^{11}$, a maior precisão e acurácia são dadas pela temperatura timpânica, seguida pela temperatura da bexiga, nasofaringe e esôfago. Temperaturas da axila têm menor acurácia do que a de outros locais ${ }^{11}$.

A temperatura central é muito próxima a do hipotálamo, região do cérebro na qual ocorre o controle central de impulsos termorreguladores provenientes de todo o organismo. $\mathrm{O}$ hipotálamo recebe irrigação sangüínea por meio da artéria cerebral anterior, que é ramo da artéria carótida interna, enquanto a membrana timpânica é irrigada por ramo da artéria carótida externa. Assim, acredita-se que a temperatura timpânica no homem estima, de forma fidedigna, a temperatura central.

Em pacientes submetidos à anestesia geral, ao se compararem as temperaturas retal, esofágica e timpânica, obteve-se boa correlação entre as temperaturas esofágica e timpânica. Porém, a temperatura retal apresentou sempre valores mais elevados do que os dos demais, durante a ocorrência de leve hipotermia no intra-operatório ${ }^{12}$. No entanto, outros autores ${ }^{13}$ demonstraram que a temperatura retal correlaciona-se muito bem com a temperatura timpânica, durante a anestesia geral e a anestesia subaracnóidea.

\section{Referências}

1. Sessler DI, Sladen RN - Mild intraoperative hypothermia. N. Engl J Med 1997; 336: 1730-1737.

2. Sessler DI. Consequences and treatment of perioperative hypothermia. Anesthesiol Clin North Am 1994; 12: 425-456. 
3. Gyton AC. Body temperature, temperature regulation and fever. In: Gyton AC, Hall JE - Textbook of Medical Physiology. 9o ed. Philadelphia: WB Saunders, 1996; 911-922.

4. Buggy DJ, Crossley AWA. Thermoregulation, mild perioperative hypothermia and postanesthetic shivering. Br J Anaesth 2000; 84: 615-628.

5. Dikenson AH. Specific responses of rat raphe neurones to skin temperature. J Physiol (Lond) 1977; 273: $277-293$.

6. Sessler DI. Temperature monitoring. In: Miller RD - Anesthesia. New York: Churchill Livingstone, 1994; 1363-1382.

7. Bissonette B. Thermoregulation and paediatric anaesthesia. Current Opinion in Anesthesiology 1993; 69: 537-542.

8. Lopez M, Sessler DI, Walter K, et al. Rate and gender dependence of the sweating vasoconstriction and shivering thresholds in humans. Anesthesiology 1994; 80: 780-788.

9. Khan F, Spence VA, Belch JJF. Cutaneous vascular responses and termoregulation in relation to age. Clin Science 1992; 82: 521-528.

10. Camus Y, Delva AE, Bossard M, et al. Prevention of hypothermia by cutaneous warming with new eletric blankets during abdominal surgery. Br J Anaesth 1997; 79: 796-797.

11. Cork RC, Vaughan RW, Humphey LS. Precision and accuracy of intraoperative temperature monitoring. Anesth Analg 1983; 62: 211-214.

12. Benzinger M. Tympanic thermometry surgery and anesthesia. JAMA 1969; 209: 1207-1211.

13. Cattaneo CG, Frank SM, Hesel TW, et al. The accuracy and precision of body temperature monitoring methods during regional and general anesthesia. Anesth Analg 2000; 90: 938-945. 